\title{
Correction to: Public health impact and cost effectiveness of routine childhood vaccination for hepatitis a in Jordan: a dynamic model approach
}

\author{
Wail A. Hayajneh ${ }^{1 *}$, Vincent J. Daniels ${ }^{2}$, Cerise K. James ${ }^{3}$, Muhammet Nabi Kanıbir ${ }^{2}$, Matthew Pilsbury ${ }^{2}$, \\ Morgan Marks², Michelle G. Goveia², Elamin H. Elbasha², Erik Dasbach ${ }^{2}$ and Camilo J. Acosta ${ }^{2}$
}

\section{Correction to: BMC Infect Dis (2018) 18(1):119 https://doi.org/10.1186/s12879-018-3034-8}

Following publication of the original article [1], the authors noted the following:

1. an omission of the maternally immune population from the calculation of the total vaccine cost.

2. an inaccurate representation of the Jordan population structure in the demographic model

The first issue was addressed by including all vaccinated population in the vaccine cost calculation.

The second issue was addressed by modifying the demographic portion of the model as follows. The model now assumes a constant population age distribution, a constant fertility rate, and a fixed birth cohort size consistent with 2015 Jordan population data [2-4]. To satisfy these model input assumptions we relaxed the previously required constant population size requirement to allow a constant population growth rate of $1.98 \%$ per year.

After applying these two changes to the model, the corrected base-case results continue to support the overall conclusion that the vaccination program was costeffective assuming a willingness-to-pay of \$ USD 3600 per quality-adjusted life-year (QALY) (1 x per capita Jordan gross domestic product in 2015 [5]). The updated incremental cost-effectiveness ratio is \$ USD 923 per QALY. Over the 50 year analysis period, the model estimates a discounted total vaccine cost of $\$$

\footnotetext{
* Correspondence: wailh@just.edu.jo

${ }^{1}$ Department of Pediatrics, Faculty of Medicine, Jordan University of Science and Technology, PO Box 3030, Irbid 22110, Jordan

Full list of author information is available at the end of the article
}

USD 192.8 million; 6.2 million cumulative cases of hepatitis A infection avoided with more than 2.6 million of these being symptomatic cases. The updated probabilistic sensitivity analysis indicates all variations remain cost-effective and approximately $8 \%$ of variations will lead to cost-saving compared with no vaccination.

For updated results please see Additional files 1 and 2. Further detailed results are available from the authors upon request.

\section{Supplementary information}

Supplementary information accompanies this paper at https://doi.org/10. 1186/s12879-019-4533-y.

Additional file 1. Updated Results (Correction Results Details).

Additional file 2. Updated Results (Updated Tables).

\section{Author details}

${ }^{1}$ Department of Pediatrics, Faculty of Medicine, Jordan University of Science and Technology, PO Box 3030, Irbid 22110, Jordan. ${ }^{2}$ Merck \& Co., Inc., Kenilworth, NJ, USA. ${ }^{3}$ Agile-1 for Merck \& Co., Inc., Kenilworth, NJ, USA.

Published online: 28 October 2019

\section{References}

1. Hayajneh WA, Daniels VJ, James CK, et al. Public health impact and cost effectiveness of routine childhood vaccination for hepatitis a in Jordan: a dynamic model approach. BMC Infect Dis. 2018;18(1):119. https://doi.org/10. 1186/s12879-018-3034-8.

2. Department of Economic and Social Affairs Population Division. Total population (both sexes combined) by five-year age group, major area, region and country, 1950-2100. World Population Prospects: The 2015 Revision. https://esa.un.org/unpd/wpp/Download/Standard/Population/. Published 2015.

3. Department of Economic and Social Affairs Population Division. Annual Population by Age - Both Sexes. https://esa.un.org/unpd/wpp/DVD/Files/1_ 
Indicators (Standard)/EXCEL_FILES/5_Interpolated/WPP2017_INT_F03_1_ POPULATION_BY_AGE_ANNUAL_BOTH_SEXES.XIsX. Published 2017.

4. Department of Economic and Social Affairs Population Division. Births by Age of Mother. https://esa.un.org/unpd/wpp/DVD/Files/1_Indicators (Standard)/EXCEL_FILES/2_Fertility/WPP2017_FERT_F06_BIRTHS_BY_AGE_ OF_MOTHER.xIsX. Published 2017.

5. World Bank Group. World Development Indicators. https://databank. worldbank.org/reports.aspx?source=2\&country=JOR. Accessed July 2019 